Chapman University

Chapman University Digital Commons

Sociology Faculty Articles and Research

Sociology

9-7-2015

\title{
Duration of U.S. Stay and Body Mass Index among Latino and Asian Immigrants: A Test of Theoretical Pathways
}

Annie Ro

University of California - Irvine

Georgiana Bostean

Chapman University, gbostean@chapman.edu

Follow this and additional works at: http://digitalcommons.chapman.edu/sociology_articles

Part of the Medicine and Health Commons, Place and Environment Commons, Race and $\underline{\text { Ethnicity Commons, Social Statistics Commons, and the Sociology of Culture Commons }}$

\section{Recommended Citation}

Ro, A., Bostean, G., Duration of U.S. Stay and Body Mass Index among Latino and Asian Immigrants: A Test of Theoretical Pathways, Social Science \& Medicine (2015), doi: 10.1016/j.socscimed.2015.09.001.

This Article is brought to you for free and open access by the Sociology at Chapman University Digital Commons. It has been accepted for inclusion in Sociology Faculty Articles and Research by an authorized administrator of Chapman University Digital Commons. For more information, please contact laughtin@chapman.edu. 


\section{Duration of U.S. Stay and Body Mass Index among Latino and Asian Immigrants: A Test of Theoretical Pathways}

\section{Comments}

NOTICE: this is the author's version of a work that was accepted for publication in Social Science \& Medicine. Changes resulting from the publishing process, such as peer review, editing, corrections, structural formatting, and other quality control mechanisms may not be reflected in this document. Changes may have been made to this work since it was submitted for publication. A definitive version was subsequently published in Social Science \& Medicine in 2015. DOI: 10.1016/j.socscimed.2015.09.001

The Creative Commons license below applies only to this version of the article.

\section{Creative Commons License}

\section{(c) 1 (1) 9}

This work is licensed under a Creative Commons Attribution-Noncommercial-No Derivative Works 4.0 License.

\section{Copyright}

Elsevier 


\section{Accepted Manuscript}

Duration of U.S. Stay and Body Mass Index among Latino and Asian Immigrants: A Test of Theoretical Pathways

Annie Ro, Assistant Professor, Georgiana Bostean, Assistant Professor

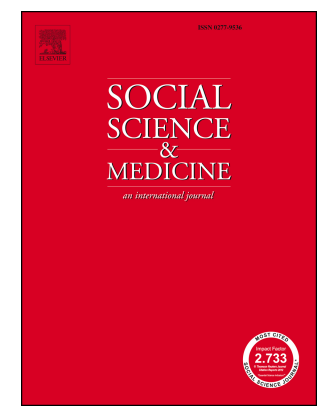

PII: $\quad$ S0277-9536(15)30106-4

DOI: $\quad$ 10.1016/j.socscimed.2015.09.001

Reference: SSM 10237

To appear in: Social Science \& Medicine

Received Date: 24 February 2015

Revised Date: 31 July 2015

Accepted Date: 1 September 2015

Please cite this article as: Ro, A., Bostean, G., Duration of U.S. Stay and Body Mass Index among Latino and Asian Immigrants: A Test of Theoretical Pathways, Social Science \& Medicine (2015), doi: 10.1016/j.socscimed.2015.09.001.

This is a PDF file of an unedited manuscript that has been accepted for publication. As a service to our customers we are providing this early version of the manuscript. The manuscript will undergo copyediting, typesetting, and review of the resulting proof before it is published in its final form. Please note that during the production process errors may be discovered which could affect the content, and all legal disclaimers that apply to the journal pertain. 
Title: Duration of U.S. Stay and Body Mass Index among Latino and Asian Immigrants: A Test of Theoretical Pathways

Annie Ro (Corresponding Author)

Assistant Professor

UC Irvine

Program in Public Health

Anteater Instruction and Research Building (AIRB)

Room 2036

653 E. Peltason Road

Irvine, CA 92697-3957

Phone: 949-824-6185

Fax: 949-824-0529

annie.ro@uci.edu

Georgiana Bostean

Assistant Professor

Chapman University

Schmid College of Science \& Technology,

Wilkinson College of Humanities \& Social Sciences

1 University Drive

Orange, CA 92866

Phone: 714-516-5910

gbostean@chapman.edu 


\section{Abstract}

Studies find that longer-term immigrants have higher body mass index (BMI) than their more recently-arrived counterparts. Most interpretations of these health patterns by duration of U.S. residence rely on theories of immigrant integration; they posit that with increasing time in the United States, immigrants incorporate economically, socially, and culturally into aspects of U.S. society, and that these changes impact health. Few studies empirically examine whether these aspects of integration are indeed mediators of the association between duration of U.S. stay and BMI, and if their patterns differ across immigrant subgroups. This study examines data from the National Latino and Asian American Survey, using path analytic methods to simultaneously test six hypothesized mediators between duration and BMI: household income, English language ability, ethnic identity, family cohesion, acculturative stress and discrimination for both Latino and Asian immigrants, stratified by gender. We find little evidence for an association between duration and BMI for either Latino or Asian men. For women, duration and BMI have a significant and positive relationship, although the pathways differ between the two ethnic groups. For Latina women, household income and acculturative stress are significant indirect pathways, although they work in opposing directions. For Asian women, English proficiency and discrimination are significant indirect pathways. Our findings reveal complex pathways between duration and BMI that vary by ethnicity and gender and highlight limitations in the negative acculturation theory, which suggests that exposure to the United States should have a net negative impact on health. In contrast, our findings suggest not all groups show declining health with longer duration, as measured by BMI, and that integration processes do not always translate into health differences in the expected directions. Future research on duration patterns may need to consider alternative explanations beyond incorporation-based processes, such as cross-national health theories or age, period, cohort effects. 
Keywords: Immigrant Health; obesity; acculturation, Latinos; Asians 


\section{Introduction}

A large literature suggests that immigrants' physical health declines the longer they reside in the United States. One of the most consistent outcomes in this regard is body mass index (BMI). Among Latino immigrants, longer duration has consistently been associated with significantly higher BMI (Himmelgreen et al., 2004; for review, see Pérez-Escamilla, 2011). Some studies estimate a nearly four-fold greater risk of obesity among some longer-term Latino immigrants compared to recent immigrants (Kaplan et al., 2004). Among Asian immigrants, many studies have also found higher BMI among longer-term immigrants (Oakkar et al., 2015; Rosas et al., 2014); a review found BMI to be the physical health indicator most consistently and positively associated with duration (Ro, 2014). Body mass provides important insight into immigrants' overall health status, as it is correlated with a many other conditions, such as cardiovascular disease, diabetes mellitus, asthma, and cancer (Go et al., 2014).

Although the empirical pattern between duration and BMI has been well established, the mechanisms underlying the relationship remain unclear. Years in the United States is not a causal variable per se, but produces the context in which certain health influences arise (Hurh \& Kim, 1990). While some research has found health behaviors, English language ability, discrimination, and family cohesion to be significant pathways between time in the United States and certain health outcomes (Akresh, 2007; Cook et al., 2009; Lee et al., 2013), these studies did not consider the possibility of multiple mediators or did not specifically study BMI. Most existing research considers duration to be a proxy for acculturation processes, but the components of the concept have not been identified or tested as mediators (Salant \& Lauderdale, 2003). As such, scholars lack a clear understanding of what aspects of immigrant integration are related with both residence in the United States and BMI. 
In this paper, we develop and test a mediation path model between duration of residence and BMI that incorporates cultural and structural components of immigrant integration processes. We use an expanded acculturation model in addition to structural perspectives to identify aspects of integration that may be significant mediators between duration and BMI. Using path analysis, we test these pathways, stratifying by gender and ethnicity (Latino and Asian) to examine differences in duration experiences by social categories. In doing so, we aim to illuminate whether and how increasing time in the United States for immigrants is associated with BMI.

\section{Acculturation Models and Duration Patterns}

The majority of literature has interpreted duration-health patterns via classic acculturation theory (Redfield et al., 1936), which assumes that immigrants undergo a shift from the origin to the host culture and contends that longer duration is correlated with greater acculturation. Longer US duration is assumed to be hazardous to immigrants' health, as immigrants adopt unhealthy diets and health risks, and shed health-protective ethnic resources, such as cultural practices and ethnic diets (Rogler et al., 1991). However, acculturation theory has been criticized for assuming that immigrants move unidirectionally towards Americanized lifestyles (Hunt et al., 2004). Moreover, the theory assumes behavioral change, but this has not been well-supported empirically. While behaviors such as dietary change, smoking, alcohol use, and exercise, are associated with both duration and BMI, they do not fully mediate the relationship (Akresh, 2007; Goel et al., 2004; Gordon-Larsen et al., 2003). Additionally, health behaviors are proximate determinants of body mass and are highly influenced by structural, psycho-social, and environmental factors that precede them, such as socioeconomic issues (Allen et al., 2014). Thus, 
not only are health behaviors insufficient explanations for the duration-BMI association, but they are also preceded by numerous other factors.

More recent models of acculturation, such as the one proposed by Schwartz et al. (2010) articulate more complex integration processes by considering immigrants' cultural, social, and economic characteristics. This theory distinguishes among three components of cultural identity: cultural identification refers to the attachment to cultural groups and the positive esteem drawn from these attachments; cultural values are the belief systems associated with specific contexts or groups; cultural practices encompass language use, media preferences, social affiliations, and cultural customs and traditions. Each of these dimensions can change with longer exposure to the United States, producing psychological and social resources that have a bearing on health outcomes. This theory further acknowledges that the attitudes of receiving-society members determine the extent to which migrants are received favorably or unfavorably, which also impacts immigrants' health outcomes. These contexts of reception can encompass discrimination, acculturative stressors, or lack of access to jobs. This model suggests that there are multiple pathways between time in U.S. and BMI, and that increased duration of residence may not necessarily lead to poorer health.

Expanded acculturation models still have shortcomings, however. First, by focusing on culture, they omit structural factors such as economic integration. Economic assimilation usually refers to immigrants' earnings over time in the United States (Portes \& Rumbaut, 2006). Household income is component of socioeconomic status, which is itself is a fundamental cause of disease that determines environments and access to resources (Link \& Phelan, 1995).

Second, individual-level cultural changes are contingent on the multiple social categories "of identity, difference, and disadvantage" that individuals inhabit (Viruell-Fuentes et al., 2012). 
Therefore, certain social groups may have unique relationships among duration, BMI, and any potential mediators. Two key social categories in this regard are gender and ethnicity. While the relationship between longer duration and higher BMI for Latinos is relatively consistent, the association for Asians is weaker and varies across studies (Goel et al., 2004; Kaushal, 2009; OzaFrank \& Narayan, 2010). There are also gender differences within ethnicities. The association between increased body weight and duration has been stronger for Latino men than women (Antecol \& Bedard, 2006; Sánchez-Vaznaugh et al., 2009), although some studies have found the opposite (Abraído-Lanza et al., 2005). Research on Asians has suggested that Asian women have greater weight gain with time in the U.S. than men (Lauderdale \& Rathouz, 2000). Given the unique migration histories, demographic characteristics, and incorporation experiences between Latinos and Asians and men and women, it is important to consider how complex integration processes vary by gender and ethnicity.

\section{Conceptual Framework}

Figure 1 presents our conceptual framework. In this study, we expand upon Schwartz's model of acculturation and use structural perspectives to test multiple pathways through which immigrants' duration of U.S. residence may be associated with BMI. This model builds upon the current literature by incorporating cultural, social, and economic factors that have been identified as dimensions of acculturation, but their role as mediators between duration and BMI has yet to be tested. We explore six mediators: cultural identity (as measured through ethnic identity), cultural values (family cohesion), cultural practices (English language proficiency), contexts of reception (discrimination, acculturative stress), and economic assimilation (household income). We examine these multiple mediators using path analysis, which allows us to test not only whether components of acculturation differ by duration of residence, but also whether those 
translate into BMI differences. To address the possibility that integration experiences differ across important social categories, we examine the model separately by ethnicity and gender.

\section{Ethnic Identity}

Ethnic identity is a common component of acculturation and health studies (Escobar \& Vega, 2000) and refers to identification with one's origin group. It can encompass both sense of identity and social relations and is often measured as how close one feels to, and how much time they prefer to spend with, co-ethnics (Phinney \& Ong, 2007). Empirical evidence for the relationship between ethnic identity and U.S. length of stay is scant, but longitudinal studies find that ethnic identity decreases over time for Latinos adolescents (Pahl \& Way, 2006). Other work on Mexican families suggests that ethnic identity diminishes across generations (Jiménez \& Fitzgerald, 2007). Yet more recent theories propose that the extent to which minority group members maintain their ethnic identity depends on their societal reception in the United States (Waters, 1990).

Ethnic identity may be protective against higher body weight, as it implies a distance from presumed unhealthy American diets and behaviors and is also a buffer against healthdeteriorating stressors (Chae et al., 2008). However, the empirical evidence on this is relationship is mixed. For example, a more "Americanized" ethnic orientation is associated with higher fat intake, but also more physical activity among Asian Indian immigrants (Jonnalagadda \& Diwan, 2005).

\section{Family Cohesion}

The tendency to place family needs above those of its' individual members, often called familism, is a central value of Asian and Latino cultures (Sabogal et al., 1987; Yee et al., 2009). Familism is among the core concepts included in acculturation and health studies (Escobar \& 
Vega, 2000; for review, see Perez \& Cruess, 2014), yet evidence about whether familism changes with duration of residence, and how it impacts health, is mixed. The most common argument is that familism declines with time in the U.S. or across immigrant generations, which some studies find evidence for (Almeida et al., 2009). Others have found that only some aspects of familism change with duration of U.S. stay (Sabogal et al., 1987).

Family cohesion, or feelings of solidarity and loyalty, is among the familism aspects considered to be health-protective, particularly for Latinos (Gallo et al., 2009). Cohesion may provide psycho-social benefits, such as social support for healthy behaviors such as exercise. Indeed, studies using the NLAAS data have found mental health benefits of family cohesion (Rivera et al., 2008). On the other hand, family cohesion may hinder healthy behaviors, for instance, through individuals prioritizing other family members' needs over their own well-being (Perez \& Cruess, 2014). One study found that adherence to a weight management plan that included diet and exercise was lower among women who expressed greater familism, including cohesion (Austin et al., 2013). Other studies have found no relationship of family cohesion to health when other aspects of family relationships are controlled (Bostean, 2010). Family cohesion remains prominent in acculturation and health studies despite mixed evidence about its association with time in the U.S., and health, particularly obesity.

\section{English Proficiency}

English language proficiency generally improves among immigrants with increasing duration of U.S. residence (Chiswick \& Miller, 1998). Although English proficiency is categorized as a cultural practice in Schwartz's model, it can encompass several aspects of integration. It is often used as a marker of cultural change because language is purportedly the key to embeddedness in an ethnic community (Ying et al., 2007). Yet language proficiency also 
has structural implications, as it is a necessary resource that enhances one's ability to navigate the host culture, and requisite for labor market and educational attainment (Gee et al., 2010).

English proficiency may be associated with BMI, although evidence for the direction is mixed. Among Latino immigrants, some find that better English proficiency is associated with higher BMI (Himmelgreen et al., 2004), while others find the opposite when examining English language use at the workplace (Akresh, 2007). There has been little work on the relationship between English use and BMI among Asians, although greater English proficiency has been associated with better self-rated health (Gee et al., 2010), which is correlated with BMI (Okosun et al., 2001). Language may affect BMI through its association with mental health. Among both Latinos and Asians, English proficiency has been associated with increased psychological distress (Zhang et al., 2012); poorer mental health, in turn, has been associated with increased BMI (Rosmond et al., 1996).

\section{Perceived Discrimination}

As immigrants integrate into the United States, they may face discrimination due to their race, nativity, language ability, or other social characteristics. If we consider duration a proxy for exposure to the United States social setting, longer-term immigrants should report more discrimination than their recently-arrived counterparts because they have had a longer "exposure period" in which to experience discriminatory events (Gee et al., 2006). Goto et al. (2002) found that Chinese immigrants who have lived in the United States longer reported more unfair treatment due to their race or ethnicity. Prior research using the same dataset as our study finds that perceived discrimination is linked with increased obesity (Gee et al., 2008). However, there may be racial and ethnic variation in the association between discrimination and body mass (Hunte \& Williams, 2009). 


\section{Acculturative Stressors}

Acculturative stressors, or "conditions of threat, challenge, demands, or structural constraints" (Wheaton et al., 2013) related to acculturation, may influence body mass by increasing stress (Berry, 2006). Stress may arise from, for instance, social interactions, cultural adjustment, guilt from leaving family members, or homesickness (Berry, 1997). Acculturative stressors presumably decrease with time in the U.S., as immigrants' social networks and support increase, become accustomed to and able to function in their host society, and so on (Caplan, 2007). However, while sociocultural adaptation (i.e., how well the individual can manage daily life in the new context) generally increases linearly with time (Berry, 2006), longer-term Asian immigrants have reported more stress than their more-recently arrived counterparts (Uppaluri et al., 2001). Thus, it is likely that duration of residence is associated with acculturative stressors differently for different groups.

Acculturative stressors are associated with poorer health (Berry, 2006; Torres \& Wallace, 2013). The physical impact of stressors may reflect coping patterns, the physiological accumulation of psychosocial stressors (i.e., 'wear and tear' on the body), or the indirect consequences of regularly confronting barriers to health-promoting factors, such as appropriate employment or adequate medical care (Williams et al., 2010). Stress is associated with obesity (Dallman et al., 2003), with at least one of the mechanisms being chronic inflammation in the body (Fuligni et al., 2009; Robles et al., 2005).

\section{Household Income}

Economists have long found that immigrants' incomes increase with longer duration in the United States (Chiswick, 1978). This has important health implications, as income gains provide access to health-enhancing resources such as health care, healthier foods, and housing in 
socioeconomically advantaged neighborhoods. However, scholars increasingly question whether upward income mobility will apply to more all immigrant groups uniformly and if some groups experience downward assimilation into the lower classes (Portes \& Zhou, 1993). Thus, there is mixed evidence about how duration is associated with BMI for different immigrant groups. Income is generally inversely related to obesity among women in developed countries (McLaren, 2007). This also appears to be the case for men, although the relationship is not as consistent (Chang \& Lauderdale, 2005). Other research suggests that the relationship of income and body weight varies across different racial and ethnic groups. For example, greater income is associated with heavier body weight among Mexican men (Chang \& Lauderdale, 2005), while there is only a weak association among Asian immigrants (Lauderdale \& Rathouz, 2000).

\section{Methods}

\section{Data}

We examined the 2003 National Latino and Asian American Study (NLAAS), the largest U.S. nationally-representative survey of Latinos and Asian Americans. This was the ideal dataset to explore our research questions because it contains a wide range of incorporation measures. We limited our sample to foreign-born working-age adults between 18 and 64 years of age because duration-health patterns attenuate in older ages (Ro \& Gee, 2012). We used case-wise deletion for observations missing data on key measures, which was approximately $5 \%$ of our sample and below the threshold recommended for imputation (Tabachnick \& Fidell, 2007). Our final analytic sample size was 2,782 (Latino men=629; Asian men=673; Latina women=727; Asian women=753). 


\section{Dependent Variable}

Body Mass Index - This was calculated using the standard CDC formula: weight in lbs/height in inches ${ }^{2} * 703$ (Centers for Disease Control and Prevention, 2015). Height and weight were self-reported by the respondents.

\section{Mediators}

Ethnic Identity- Four items asked respondents whether they identify with others of the same racial/ethnic descent, feel close in their ideas/feelings with people of the same racial descent, how much time they would like to spend with people who are of the same racial and ethnic group, and the importance for people of the same racial/ethnic group to marry within the group. The responses ranged from 1 to 4 , with 1 being high agreement with the statement and 4 being low agreement with the statement. We reverse coded the responses and took the mean value across the four questions. The range was $1-4$, with 4 indicating high ethnic identity (Latinos $\alpha=0.60$, Asians $\alpha=0.67$ ).

Family Cohesion- Ten items asked respondents about family characteristics, such as whether family members respect one another, share values, express feelings, trust and confide in one another, or feel close to one another. Responses to each question ranged from 1 to 4 , with 1 indicating strongly agree and 4 indicating strongly disagree. We reverse coded the items and calculated the mean across 10 items. The range was 1-4, with 4 indicating high family cohesion (Latinos $\alpha=0.93$, Asians $\alpha=0.92$ ).

English Language Proficiency - Three items asked respondents how well they speak, read, and write English. We recoded the responses to be binary with 1 being "excellent or good" versus all others (Gee et al., 2010), and calculated the mean of the summed scores. The range was 0 to1, with 1 indicating the highest English proficiency (Latinos $\alpha=0.97$, Asians $\alpha=0.96$ ). 
Everyday Interpersonal Discrimination -Nine items asked respondents about the frequency of certain discriminatory experiences, such as being treated with less courtesy than others, being called names or being threatened or harassed (Williams et al., 1997). Responses for each item range from 1 "Almost Everyday" to 6 "Never". We reverse-coded the items and calculated the mean across the nine items. The range of the summary variable was 0 to 5 , with 5 being highest discrimination (Latinos $\alpha=0.89$, Asians $\alpha=0.90$ ).

Acculturative Stressors -Ten items asked respondents about stressful migration-related experiences, such as feeling guilty about leaving family/friends in the country of origin, whether they receive the same level of respect in the US as in the country of origin, and whether it is difficult for them to find work because of their nativity status (yes $=1$, no $=0$ ). These questions were only asked of the foreign-born who had immigrated to the U.S. and not of the U.S.-born, because many of the items referred to the immigration experience. We averaged across ten questions, for a scale range of 0 to 1 , with 1 indicating the highest acculturative stress (Latinos $\alpha=0.67$, Asians $\alpha=0.54)$.

Household Income - The respondent's household income was self-reported on a 1000 dollar scale, top-coded at $\$ 200,000$.

\section{Covariates}

We controlled for potential confounding factors: age, age squared (because of the curvilinear relationship with BMI), employment (employed vs. non-employed), marital status (married vs. non-married) and years of education. Initial analyses controlled for additional covariates, including a dummy variable for child migration, but were not significant predictors thus are excluded from final analyses. 


\section{Analysis}

Given the variety of possible mechanisms between duration and BMI, we utilized a multiple mediator path analysis. Path analytic models enabled us to examine all variables simultaneously, reduce potential bias from omitted variables, and decompose and calculate the individual indirect effects of each mediator and compare them to one another (Preacher \& Hayes, 2008).

We conducted all analyses in Stata 13 and accounted for the complex survey design with the svy command. We first examined the descriptive statistics for the sample, testing for group differences across ethnicity and gender using a Wald Test. Multivariate analyses used a recursive six-mediator path model using the Stata group option, which calculates the path coefficients for each ethnic and gender subgroup separately. We estimated the path coefficients for all mediators simultaneously, controlling for covariates and other mediators. The path model estimated a direct path between duration and BMI, and indirect pathways via ethnic identity, family cohesion, English proficiency, discrimination, acculturative stress, and household income. The indirect paths are the product of the direct path between duration and the mediator and the direct path between the mediator to BMI. We allowed the control variables to covary to account for the fact that there may be correlation among the control variables (Acock, 2013). We decomposed the total effect of duration on BMI into direct effects and individual indirect effects for each mediator to assess the significance of each indirect pathway.

\section{Results}

\section{Descriptive Results}

Table 1 shows the demographic characteristics for Latino men, Latino women, Asian men, and Asian women. All groups have similar mean ages and marriage rates. Asians have 
higher education than Latinos and men across both groups have a higher employment rate than women. Latino men have the highest employment rate (83\%) compared to all other groups. Latinos have higher BMIs than Asians, and Asian women have the lowest BMI. BMI is higher among longer-term immigrants for all groups. Latina women have the greatest BMI difference between recent and longer-term immigrants (25.9\% compared to $29.1 \%$, respectively). Latinos and Asians have similar levels of ethnic identity and family cohesion. Asians have higher English proficiency and household income than Latinos, while Latinos experience higher levels of acculturative stress. Latina women report the lowest levels of discrimination and Asian men report the highest.

\section{Path Analysis Results}

Table 2 displays the path coefficients for Latino and Asian men. The left panel of the table displays the unstandardized and standardized coefficients of the direct paths between duration and the six mediators. Among Latino men, longer-term immigrants have better English proficiency $(\mathrm{B}=0.11 \mathrm{p}<.001)$ and higher household income $(\mathrm{p}<.001)$ with each higher duration category. By contrast, acculturative stress $(\mathrm{B}=-.06, \mathrm{p}<.001)$ is lower among immigrants of longer duration. Turning to the association between each mediator and BMI (right panel of table), none of the mediators is associated with BMI for Latino men, nor is there an association with duration after accounting for the six mediators and covariates.

For Asian men, duration is positively associated with household income $(B=12.56$, $\mathrm{p}<.05)$, while acculturative stress is negatively associated $(\mathrm{B}=-0.03, \mathrm{p}<.05)$. Of the mediators, only discrimination is significantly associated with BMI, with greater perceived discrimination being correlated with higher $\mathrm{BMI}(\mathrm{B}=0.75, \mathrm{p}<.05)$. Similar to Latino men, duration is not 
significantly associated with BMI for Asian men after accounting for the mediators and covariates.

Table 3 displays results for women. For Latina women, longer duration of residence is associated with greater English proficiency $(B=0.11, \mathrm{p}<.001)$ and household income $(B=5.52$, $\mathrm{p}<.001)$. In contrast, acculturative stress $(\mathrm{B}=-.08, \mathrm{p}<.001)$, discrimination $(\mathrm{B}=-.05, \mathrm{p}<.10)$ and family cohesion $(B=-.06, p<.001)$ are lower among those with longer duration. Several mediators are associated with BMI for Latina women. Higher BMI is associated with lower household income $(B=-0.02, p<.001)$, lower acculturative stress $(B=-2.42, p<.001)$, greater discrimination $(\mathrm{B}=0.68, \mathrm{p}<.001)$, and more family cohesion $(\mathrm{B}=1.13, \mathrm{p}<.001)$. Duration remains significantly associated with BMI after controlling for mediators and covariates $(B=0.61, \mathrm{p}<.05)$.

For Asian women, longer duration is positively associated with English proficiency $(\mathrm{B}=0.07, \mathrm{p}<.001)$, household income $(\mathrm{B}=5.35, \mathrm{p}<.10)$ and discrimination $(\mathrm{B}=0.07, \mathrm{p}<.10)$. Ethnic identity $(\mathrm{B}=-.09, \mathrm{p}<.05)$ and acculturative stress $(\mathrm{B}=-.03, \mathrm{p}<.05)$ are negatively associated with increasing duration. Of the six mediators, English proficiency $(B=1.55, \mathrm{p}<.05)$ and discrimination $(\mathrm{B}=0.64, \mathrm{p}<.05)$ are significantly and positively associated with BMI. Duration is not associated with BMI after controlling for mediators and covariates.

\section{Total, Direct and Indirect Effects}

We decomposed the total effects into direct and indirect effects of duration and the six mediators on BMI for men (Table 4) and women (Table 5). The total effect is the sum of the individual indirect effects via the six mediators and the direct effect between duration and BMI. The individual indirect effect for each mediator multiplies the path coefficient between duration and the mediator with the path coefficient between the mediator and BMI. The combined indirect effect represents the sum of the six indirect mediator pathways. For Latino and Asian men, none 
of the total, direct, or indirect effects are significant, suggesting there is no significant relationship between duration and BMI for men.

For Latina women (Table 5), the total effect of duration on $\mathrm{BMI}$ is significant $(\mathrm{B}=0.65$, $\mathrm{p}<.05)$, as is the direct effect $(\mathrm{B}=0.61, \mathrm{p}<.05)$. Two mediators have a significant indirect effect on BMI for Latina women: household income and acculturative stress. Increased duration is associated with higher household income, which is in turn associated with lower BMI for Latina women $(B=-.09, p<.05)$. The indirect effect via acculturative stress is positive $(B=0.18, p<.01)$, because the component coefficients are both negative. With longer duration, Latina women report lower acculturative stress, which is associated with higher BMI, resulting in a positive indirect effect.

For Asian women, the total effect between duration and $\mathrm{BMI}$ is significant $(\mathrm{B}=0.39$, $\mathrm{p}<.10)$. There are two significant individual indirect effects, both positive, through English proficiency and discrimination. With longer duration, Asian women report better English ability, which is associated with higher BMI. Similarly, with longer duration, Asian women report greater discrimination, which is associated with higher $\mathrm{BMI}(\mathrm{B}=0.04, \mathrm{p}<.05)$.

\section{Sensitivity Tests}

We conducted the path analysis for only those individuals with less than a high school education, as other research has found duration patterns to be more prominent among lowereducated immigrants, especially among Asians (Li \& Hummer, 2015). Those with less than a high school degree may represent a unique subsample within Asian immigrants, given their high education and proportion of student or employment visas (Ramakrishnan \& Ahmad, 2014).

The results are qualitatively similar for Latino men and Asian women. For Latina women, many of the relationships are more pronounced among those with less than a high school 
education. Education makes the most difference among Asian men; there were many more significant associations among those with lower education. For Asian men with less than a high school degree, acculturative stress is no longer significantly associated with duration while nearly all of the other mediators are. All of the mediators are significantly associated with BMI, with the exception of household income. We should note, however, that the sample sizes for the less than high school subsample are considerably smaller than the original analytic sample (Latino men n=268; Latino women $n=299$; Asian men n=85; Asian women $n=134$ ).

\section{Discussion}

We developed and tested a multiple mediator path model between years in the United States and BMI that incorporated both cultural and structural characteristics of immigrants. Overall, we find that immigrants differ in cultural and economic characteristics by duration of US residence, but the association that these factors have with BMI is weak. The few significant mediators are unique to ethnicity and gender, suggesting that acculturation processes related to years of US residence differ by social categories. Thus, even acculturation models that include multiple dimensions of cultural change, as well as contexts of reception, only partially explain the relationship between duration and BMI among immigrant groups.

First, it does not appear that duration is associated with BMI for either Latino or Asian men. While several of the mediators are associated with longer duration, such as a higher household income and lower acculturative stress, these mediators ultimately have no association with BMI. In general, social variables, such as education and income, have weaker associations with BMI among men compared to women, partly due to gender roles related to body image and food preparation (McLaren, 2007). Future research should consider how gender roles intersect with integration processes to produce disparate pathways for men and women. 
The lack of significant findings among men may also be attributed to unique features of our analysis. We limited our sample to immigrants possibility limiting the sensitivity to detect significant associations because of the small sample size. Furthermore, without a US-born reference group, we compared the immigrant duration groups to one another. This comparison tends to reduce statistical power (Kimbro et al., 2008).

For Latina women, duration is significantly associated with BMI. There are two significant mediators, household income and acculturation stressors, and they worked in opposing directions. Household income increased with longer duration in the United States, which was associated with lower BMI. This suggests that economic assimilation may actually be protective for Latina women in terms of their BMI.

In contrast, acculturative stressors are lower for longer-term Latina immigrants, yet having fewer acculturative stressors is actually associated with a higher BMI. This latter finding is especially surprising, given existing research that suggests that acculturative stress and stressors are associated with worse health outcomes (Finch et al., 2001; Torres \& Wallace, 2013). Many existing studies, however, have examined stress as opposed to stressors. Exposure to stressors does not necessarily lead to increased stress and depends on other factors such as availability of coping resources (Pearlin et al., 1981). It may be that Latina women, despite being exposed to acculturative stressors, do not experience the psychological and physiological manifestation of stress because they have psychosocial coping resources (e.g., social support, religiosity, positive framing) which reduce negative appraisals of these stressors. For instance, Latinos have more social support than Asians (Almeida et al., 2009). Research on ethnic differences in stress and coping is still needed (Pearlin \& Bierman, 2013), but as an example, Mexican immigrants are more likely to use effective coping strategies compared to non-Hispanic 
Whites (Farley et al., 2005). Finally, the direct effect between duration of residence and BMI remained significant even after accounting for the six mediators, suggesting that other potential mediators should be explored in future research.

The pathways between duration and BMI for Asian women were distinct from Latina women, bolstering the argument that integration experiences are not universal and vary across social groups. For Asian women, discrimination is a positive and significant mediator; longerterm immigrants experience more discrimination, which is associated with higher BMI. This finding aligns with other research that has found discrimination to be associated with higher BMI among longer-term Asian immigrants (Gee et al., 2008). Previous research did not stratify by gender, but our results suggest that this relationship is especially strong among Asian women.

The pathway via English proficiency was positive and significant for Asian women; English proficiency was better among longer-term immigrants, which was associated with higher BMI. While English proficiency is thought to be a key tool in accessing health care and other broader social determinants of health and illness (e.g., socioeconomic position) that would improve health, it can also be associated with worse health by being a marker for exposure to unhealthy diet and lifestyle (Gee et al., 2010). In the case of Asian women, it appears that their improving English proficiency is an example of the latter case. We were unable to examine health behaviors as an explanation for the link between English proficiency and BMI due to limitations of our survey data. Understanding potential intermediate mechanisms that help to explain why English proficiency is associated with greater BMI is an important area for future research.

There are several benefits to using path analytic models to examine multiple mediators over the traditional mediator model that uses step-wise regression (Baron \& Kenny, 1986). Path 
analytic models enable us to examine all variable simultaneously and reduce potential bias from omitted variables (Preacher \& Hayes, 2008). Path analytic models further enable us to decompose and calculate the individual indirect effects of each mediator and compare them to one another. Future research can employ more elaborate modeling strategies, such as full structural equation models, to consider latent variables that were not explicitly included in the model. In addition, results should be interpreted only as associational, as the data were crosssectional. Because we only examined immigrants at a single time point, we cannot determine whether the observed effect of duration is truly due to increased length of residence in the U.S., or whether it may reflect cohort differences.

Immigrant health research has long relied on immigrant incorporation theories to interpret variation in health status across length of US residence. Our findings suggest that aspects of immigrants' cultural, social, and economic characteristics are associated with longer duration, but their role on BMI is limited. Therefore, studies are needed that examine the complex interrelationships between various factors associated with both duration of U.S. residence and health outcomes. Moving beyond acculturation-based processes, future research might also consider issues such as cross-national theories of health or age, period, and cohort effects (Acevedo-Garcia et al., 2012). 
Table 1. Descriptive Characteristics by Ethnicity and Gender

\begin{tabular}{|c|c|c|c|c|c|}
\hline & $\begin{array}{c}\text { Latino } \\
\text { Men }\end{array}$ & $\begin{array}{c}\text { Asian } \\
\text { Men }\end{array}$ & $\begin{array}{c}\text { Latina } \\
\text { Women }\end{array}$ & $\begin{array}{c}\text { Asian } \\
\text { Women }\end{array}$ & \\
\hline $\mathrm{N}$ & 629 & 673 & 727 & 753 & \\
\hline Age (mean) & 36 & 39 & 37 & 40 & $* *$ \\
\hline Years of Education (mean) & 10 & 14 & 10 & 14 & $* *$ \\
\hline Married & $75 \%$ & $74 \%$ & $69 \%$ & $78 \%$ & $*$ \\
\hline Employed & $83 \%$ & $78 \%$ & $53 \%$ & $60 \%$ & $* *$ \\
\hline BMI (mean) & 27.9 & 24.7 & 27.3 & 23.3 & $* *$ \\
\hline \multicolumn{6}{|l|}{ BMI by Duration } \\
\hline Less than 5 years & 26.4 & 23.8 & 25.9 & 22.9 & $* *$ \\
\hline 5-10 Years & 27.7 & 24.3 & 26.1 & 21.9 & $* *$ \\
\hline 11-20 Years & 27.7 & 24.9 & 26.8 & 23.3 & $* *$ \\
\hline $20+$ Years & 28.8 & 25.2 & 29.1 & 24.3 & $* *$ \\
\hline Ethnic Identity & 3.09 & 3.14 & 3.12 & 3.11 & \\
\hline Family Cohesion & 3.7 & 3.71 & 3.65 & 3.7 & \\
\hline English Proficiency & 0.26 & 0.64 & 0.27 & 0.59 & $* *$ \\
\hline Discrimination & 0.79 & 0.83 & 0.56 & 0.73 & $* *$ \\
\hline Acculturative Stressors & 0.28 & 0.22 & 0.29 & 0.21 & $* *$ \\
\hline Household Income & 40,629 & 79,165 & 37,776 & 73,542 & $* *$ \\
\hline
\end{tabular}

Source: Authors' calculations using National Latino and Asian American Survey (2002-2003).

Note: $* * \mathrm{p}<.01, * \mathrm{p}<.05$ (two-tailed test): Wald test for difference across four sub-groups. Ranges: Ethnic Identity (0-1), Ethnic Identity (1-4), Family Cohesion (1-4), Acculturative Stressors (0-1), Discrimination (0-5) with higher values indicating higher levels of the construct. 
Table 2. Path Coefficients for Men

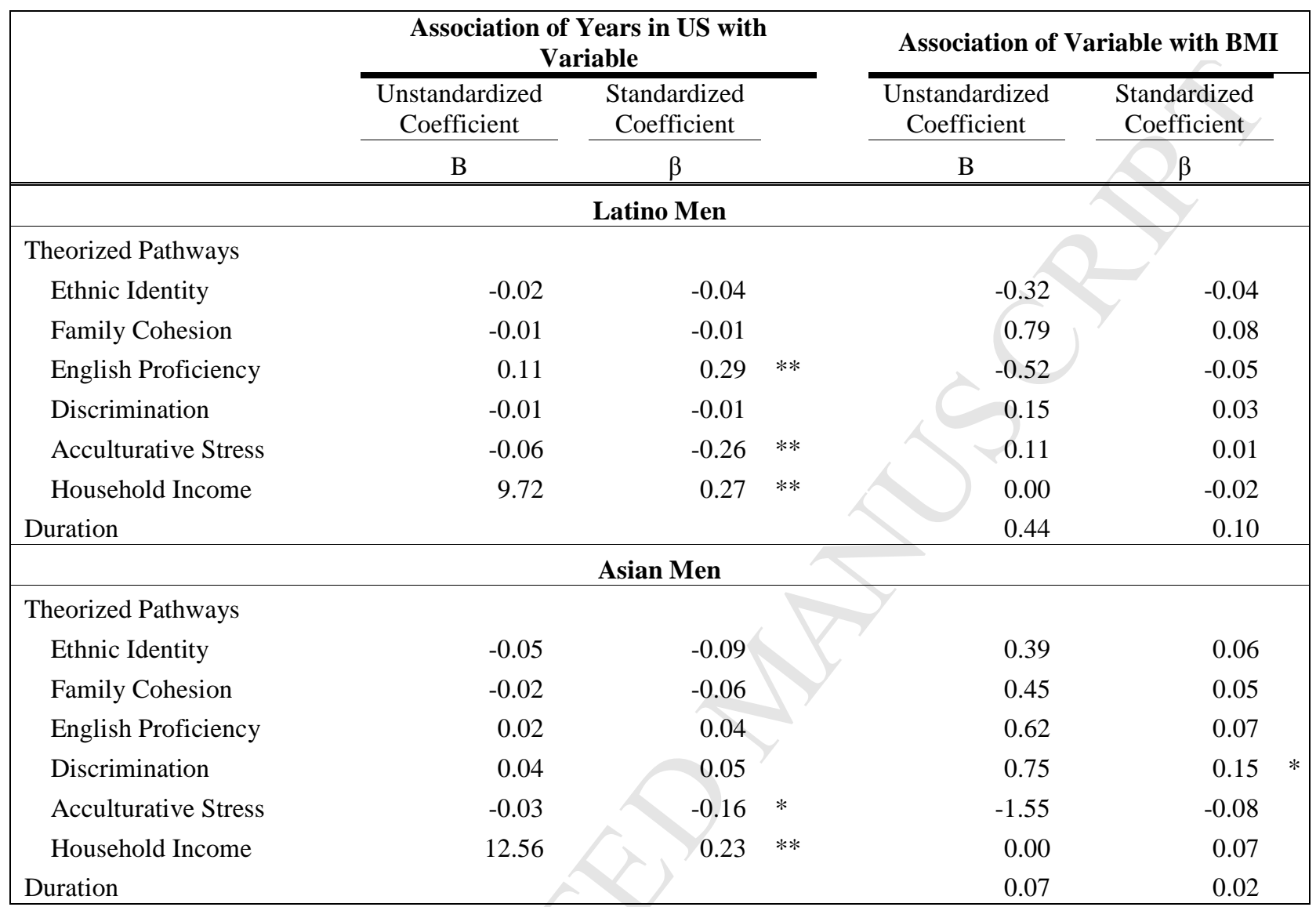

Source: Authors' calculations using National Latino and Asian American Survey (2002-2003).

Note: $* * \mathrm{p}<.01, * \mathrm{p}<.05$ (two-tailed test). Path models controlled for age, age squared, education, marital status, employment status. 
Table 3. Path Coefficients for Women

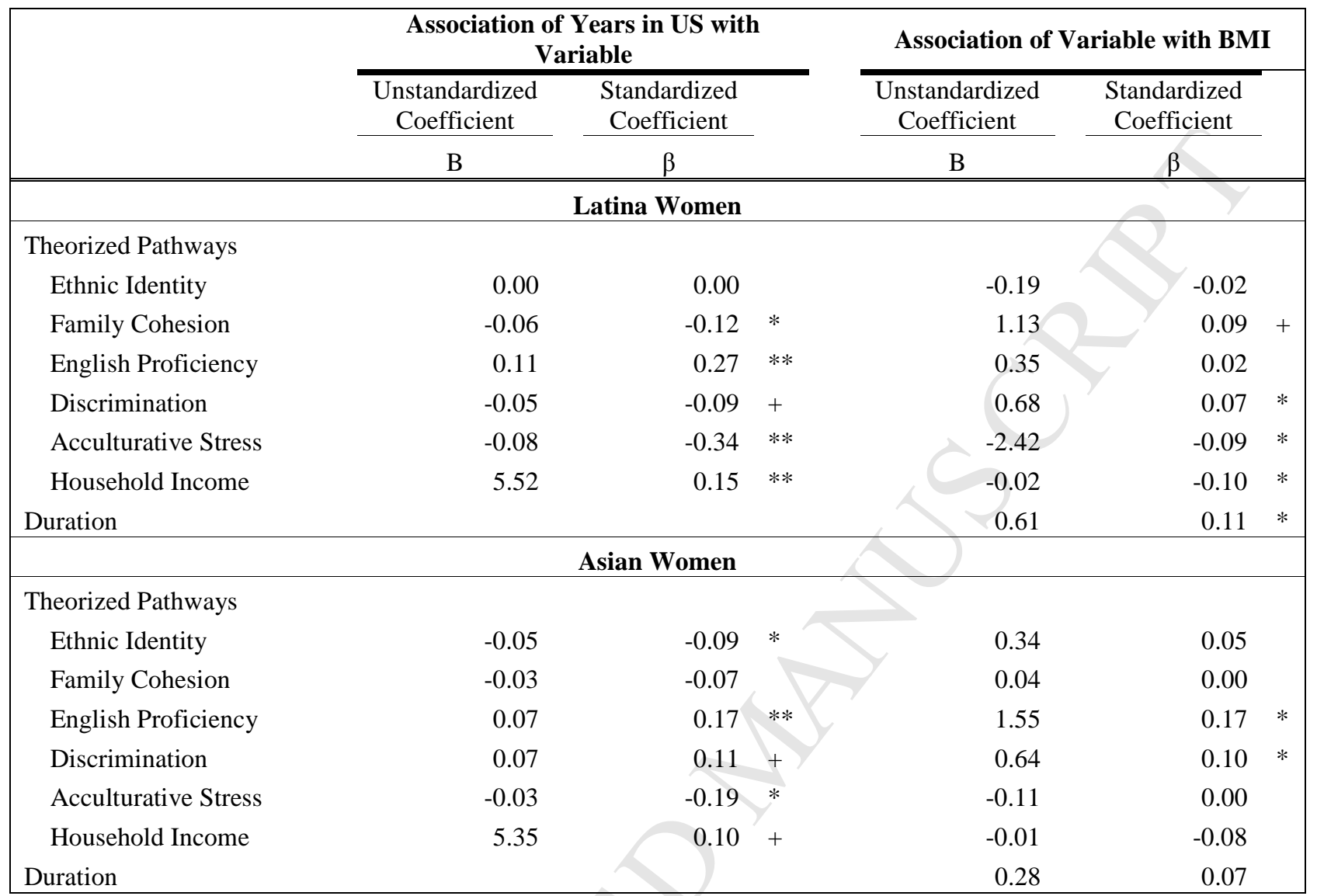

Source: Authors' calculations using National Latino and Asian American Survey (2002-2003).

Note: $* * \mathrm{p}<.01, * \mathrm{p}<.05,+\mathrm{p}<.10$ (two-tailed test). Path models controlled for age, age squared, education, marital status, employment status. 
Table 4. Decomposition of Effects, Men

\begin{tabular}{|c|c|c|c|c|}
\hline & \multicolumn{2}{|c|}{ Latino Men } & \multicolumn{2}{|c|}{ Asian Men } \\
\hline & Unstandardized & Standardized & Unstandardized & Standardized \\
\hline & $\mathrm{B}$ & $\beta$ & $\mathrm{B}$ & $\beta$ \\
\hline Total Effect & 0.35 & 0.08 & 0.18 & 0.05 \\
\hline Direct Effect & 0.44 & 0.10 & 0.07 & 0.02 \\
\hline \multicolumn{5}{|l|}{ All Indirect Effects } \\
\hline Six Mediators Combined & -0.09 & -0.02 & 0.10 & 0.03 \\
\hline \multicolumn{5}{|l|}{ Indirect effect via } \\
\hline Ethnic Identity & 0.01 & 0.00 & -0.02 & -0.01 \\
\hline Family Cohesion & 0.00 & 0.00 & -0.01 & 0.00 \\
\hline English Proficiency & -0.06 & -0.01 & 0.01 & 0.00 \\
\hline Discrimination & 0.00 & 0.00 & 0.03 & 0.01 \\
\hline Acculturative Stress & -0.01 & 0.00 & 0.04 & 0.01 \\
\hline Household Income & -0.02 & -0.01 & 0.05 & 0.02 \\
\hline
\end{tabular}

Source: Authors' calculations using National Latino and Asian American Survey (2002-2003).

Note: $* * \mathrm{p}<.01, * \mathrm{p}<.05,+\mathrm{p}<.10$ (two-tailed test). Path models controlled for age, age squared, education, marital status, employment status. 
Table 5. Decomposition of Effects, Women

\begin{tabular}{|c|c|c|c|c|c|c|}
\hline & \multicolumn{2}{|c|}{ Latina Women } & & \multicolumn{2}{|c|}{ Asian Women } & \\
\hline & Unstandardized & Standardized & & Unstandardized & Standardized & \\
\hline & $\mathrm{B}$ & $\beta$ & & $\mathrm{B}$ & $\beta$ & \\
\hline Total Effect & 0.65 & 0.11 & $*$ & 0.39 & 0.10 & + \\
\hline Direct Effect & 0.61 & 0.11 & $*$ & 0.28 & 0.07 & \\
\hline \multicolumn{7}{|l|}{ All Indirect Effects } \\
\hline Six Mediators Combined & 0.04 & 0.01 & & 0.11 & 0.03 & $*$ \\
\hline \multicolumn{7}{|l|}{ Indirect effect via } \\
\hline Ethnic Identity & 0.00 & 0.00 & & -0.02 & 0.00 & \\
\hline Family Cohesion & -0.06 & -0.01 & & 0.00 & 0.00 & \\
\hline English Proficiency & 0.04 & 0.01 & & 0.11 & 0.03 & $*$ \\
\hline Discrimination & -0.04 & -0.01 & & 0.04 & 0.01 & + \\
\hline Acculturative Stress & 0.18 & 0.03 & + & 0.00 & 0.00 & \\
\hline Household Income & -0.09 & -0.02 & $*$ & -0.03 & -0.01 & \\
\hline
\end{tabular}

Source: Authors' calculations using National Latino and Asian American Survey (2002-2003).

Note: $* * \mathrm{p}<.01, * \mathrm{p}<.05,+\mathrm{p}<.10$ (two-tailed test). Path models controlled for age, age squared, education, marital status, employment status 
Figure 1. Conceptual Model of Direct and Indirect Paths between Years in the United States and Body Mass Index

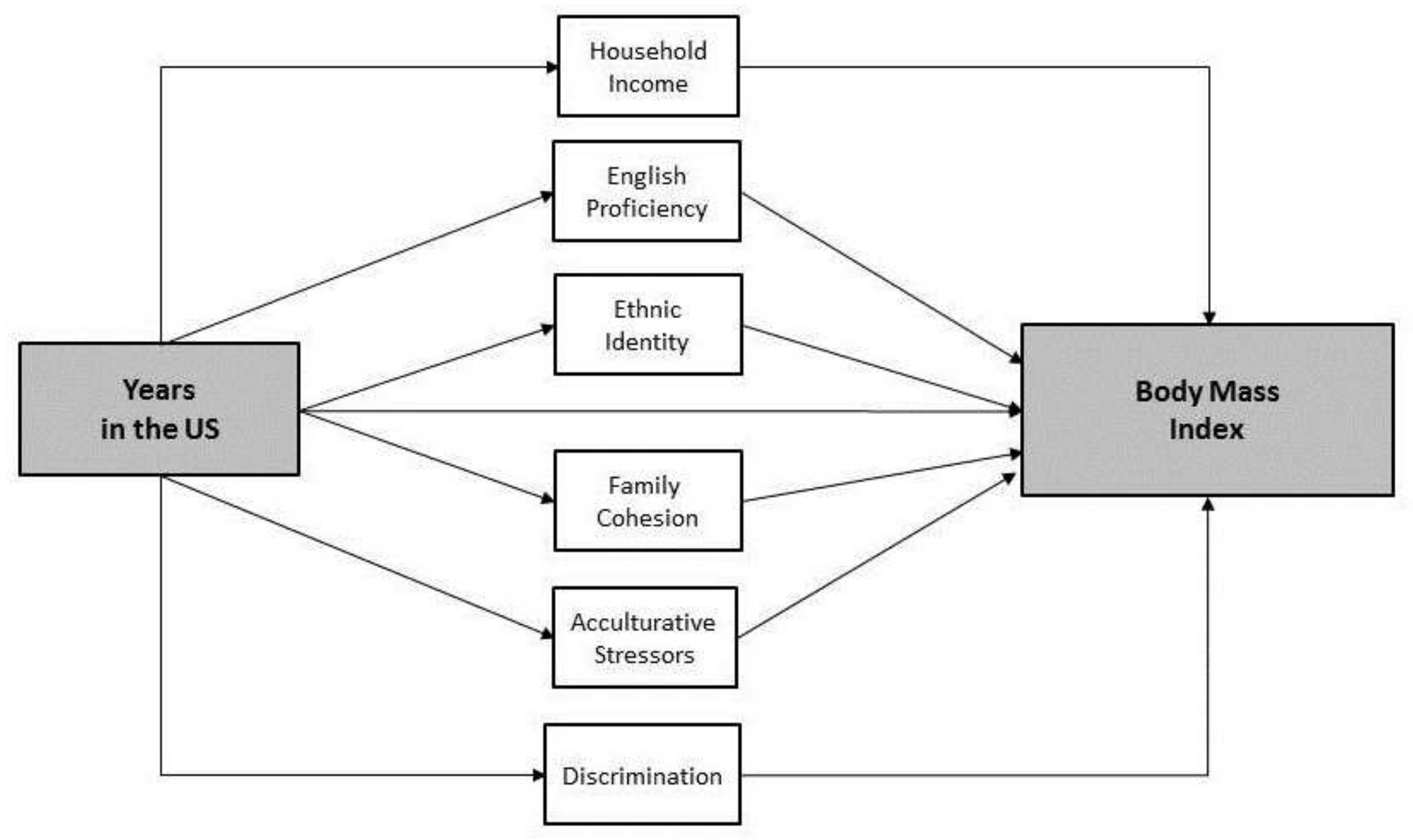




\section{References}

Abraído-Lanza, A.F., Chao, M.T., \& Flórez, K.R. (2005). Do Healthy Behaviors Decline with Greater Acculturation?: Implications for the Latino Mortality Paradox. Social Science and Medicine, 61, 1243-1255.

Acevedo-Garcia, D., Sanchez-Vaznaugh, E.V., Viruell-Fuentes, E.A., \& Almeida, J. (2012). Integrating social epidemiology into immigrant health research: A cross-national framework. Social Science and Medicine, 75, 2060-2068.

Acock, A.C. (2013). Discovering Structural Equation Modeling Using Stata. College Station, TX: Stata Press.

Akresh, I.R. (2007). Dietary assimilation and health among Hispanic immigrants to the United States. Journal of Health and Social Behavior, 48, 404-417.

Allen, J.D., Caspi, C., Yang, M., Leyva, B., Stoddard, A.M., Tamers, S., et al. (2014). Pathways between acculturation and health behaviors among residents of low-income housing: The mediating role of social and contextual factors. Social Science and Medicine, 123, 26-36.

Almeida, J., Molnar, B.E., Kawachi, I., \& Subramanian, S.V. (2009). Ethnicity and nativity status as determinants of perceived social support: Testing the concept of familism. Social Science and Medicine, 68, 1852-1858.

Antecol, H., \& Bedard, K. (2006). Unhealthy assimilation: why do immigrants converge to American health status levels? Demography, 43, 337-360.

Austin, J.L., Smith, J.E., Gianini, L., \& Campos-Melady, M. (2013). Attitudinal familism predicts weight management adherence in Mexican-American women. Journal of Behavioral Medicine, 36, 259269.

Baron, R.M., \& Kenny, D.A. (1986). The moderator-mediator variable distinction in social psychological research: Conceptual, strategic, and statistical considerations. Journal of Personality and Social Psychology, 51, 1173-1182.

Berry, J.W. (1997). Immigration, Acculturation, and Adaptation. Applied Psychology, 46, 5-34.

Berry, J.W. (2006). Acculturative Stress. In P.T.P. Wong, \& L.C.J. Wong (Eds.), Handbook of Multicultural Perspectives on Stress and Coping pp. 287-298): Springer.

Bostean, G. (2010). An Examination of the Relationship between Family and U.S. Latinos' Physical Health. Field Actions Science Reports, Special Issue 2 : Health and Migration.

Caplan, S. (2007). Latinos, Acculturation, and Acculturative Stress: A Dimensional Concept Analysis. Policy, Politics, \& Nursing Practice, 8, 93-106.

Centers for Disease Control and Prevention. (2015). About Adult Body Mass Index (BMI).

Chae, D.H., Takeuchi, D.T., Barbeau, E.M., Bennett, G.G., Lindsey, J.C., Stoddard, A.M., et al. (2008). Alcohol disorders among Asian Americans: associations with unfair treatment, racial/ethnic discrimination, and ethnic identification (the $n=$ National Latino and Asian Americans Study, 2002-2003). Journal of Epidemiology and Community Health, 62, 973-979.

Chang, V.W., \& Lauderdale, D.S. (2005). Income disparities in body mass index and obesity in the united states, 1971-2002. Archives of Internal Medicine, 165, 2122-2128.

Chiswick, B.R. (1978). The Effect of Americanization on the Earnings of Foreign-born Men. The Journal of Political Economy, 86, 897-921.

Chiswick, B.R., \& Miller, P.W. (1998). English Language Fluency Among Immigrants in the United States. Research in Labor Economics, 17, 151-200.

Cook, B., Alegría, M., Lin, J.Y., \& Guo, J. (2009). Pathways and Correlates Connecting Latinos' Mental Health With Exposure to the United States. American Journal of Public Health, 99, 2247-2254. 
Dallman, M.F., Pecoraro, N., Akana, S.F., la Fleur, S.E., Gomez, F., Houshyar, H., et al. (2003). Chronic stress and obesity: A new view of "comfort food". Proceedings of the National Academy of Sciences, 100, 11696-11701.

Escobar, J.I., \& Vega, W.A. (2000). Mental health and immigration's AAAs: Where are we and where do we go from here? Journal of Nervous and Mental Disease, 188, 736-740.

Farley, T., Galves, A., Dickinson, L.M., \& Perez, M.J.D. (2005). Stress, Coping, and Health: A Comparison of Mexican Immigrants, Mexican-Americans, and Non-Hispanic Whites. Journal of Immigrant Health, 7, 213-220.

Finch, B.K., Hummer, R.A., Kol, B., \& Vega, W.A. (2001). The Role of Discrimination and Acculturative Stress in the Physical Health of Mexican-Origin Adults. Hispanic Journal of Behavioral Sciences, 23, 399-429.

Fuligni, A.J., Telzer, E.H., Bower, J., Cole, S.W., Kiang, L., \& Irwin, M.R. (2009). A Preliminary Study of Daily Interpersonal Stress and C-Reactive Protein Levels Among Adolescents From Latin American and European Backgrounds. Psychosomatic Medicine, 71, 329-333.

Gallo, L.C., Penedo, F.J., Espinosa de los Monteros, K., \& Arguelles, W. (2009). Resiliency in the Face of Disadvantage: Do Hispanic Cultural Characteristics Protect Health Outcomes? Journal of Personality, 77, 1707-1746.

Gee, G.C., Ro, A., Gavin, A., \& Takeuchi, D.T. (2008). Disentangling the Effects of Racial and Weight Discrimination on Body Mass Index and Obesity Among Asian Americans. American Journal of Public Health, 98, 493-500.

Gee, G.C., Ryan, A., Laflamme, D.J., \& Holt, J. (2006). Self-Reported Discrimination and Mental Health Status Among African Descendants, Mexican Americans, and Other Latinos in the New Hampshire REACH 2010 Initiative: The Added Dimension of Immigration. American Journal of Public Health, 96, 1821-1828.

Gee, G.C., Walsemann, K.M., \& Takeuchi, D.T. (2010). English Proficiency and Language Preference: Testing the Equivalence of Two Measures. American Journal of Public Health, 100, 563-569.

Go, A.S., Mozaffarian, D., Roger, V.L., Benjamin, E.J., Berry, J.D., Blaha, M.J., et al. (2014). Heart Disease and Stroke Statistics-2014 Update: A Report From the American Heart Association. Circulation, 129, e28-e292.

Goel, M.S., McCarthy, E.P., Phillips, R.S., \& Wee, C.C. (2004). Obesity among US immigrant subgroups by duration of residence. Jama, 292, 2860-2867.

Gordon-Larsen, P., Harris, K.M., Ward, D.S., \& Popkin, B.M. (2003). Acculturation and overweight-related behaviors among Hispanic immigrants to the US: the National Longitudinal Study of Adolescent Health. Social Science \& Medicine, 57, 2023-2034.

Goto, S.G., Gee, G.C., \& Takeuchi, D.T. (2002). Strangers still? The experience of discrimination among Chinese Americans. Journal of Community Psychology, 30, 211-224.

Himmelgreen, D.A., Pérez-Escamilla, R., Martinez, D., Bretnall, A., Eells, B., Peng, Y., et al. (2004). The longer you stay, the bigger you get: Length of time and language use in the U.S. are associated with obesity in Puerto Rican women. American Journal of Physical Anthropology, 125, 90-96.

Hunt, L.M., Schneider, S., \& Comer, B. (2004). Should "acculturation" be a variable in health research? A critical review of research on US Hispanics. Social Science \& Medicine, 59, 973-986.

Hunte, H.E.R., \& Williams, D.R. (2009). The Association Between Perceived Discrimination and Obesity in a Population-Based Multiracial and Multiethnic Adult Sample. American Journal of Public Health, 99, 1285-1292.

Hurh, W.M., \& Kim, K.C. (1990). Adaptation Stages and Mental Health of Korean Male Immigrants in the United States. International Migration Review, 24, 456-479.

Jiménez, T.R., \& Fitzgerald, D. (2007). Mexican Assimilation. Du Bois Review: Social Science Research on Race, 4, 337-354. 
Jonnalagadda, S., \& Diwan, S. (2005). Health Behaviors, Chronic Disease Prevalence and Self-Rated Health of Older Asian Indian Immigrants in the U.S. Journal of Immigrant Health, 7, 75-83.

Kaplan, M.S., Huguet, N., Newsom, J.T., \& McFarland, B.H. (2004). The association between length of residence and obesity among Hispanic immigrants. American Journal of Preventive Medicine, 27, 323-326.

Kaushal, N. (2009). Adversities of acculturation? Prevalence of obesity among immigrants. Health Economics, 18, 291-303.

Kimbro, R.T., Bzostek, S., Goldman, N., \& Rodríguez, G. (2008). Race, Ethnicity, And The Education Gradient In Health. Health Affairs, 27, 361-372.

Lauderdale, D.S., \& Rathouz, P.J. (2000). Body mass index in a US national sample of Asian Americans: effects of nativity, years since immigration and socioeconomic status. International journal of obesity and related metabolic disorders : Journal of the International Association for the Study of Obesity, 24, 1188-1194.

Lee, S., O'Neill, A.H., Ihara, E.S., \& Chae, D.H. (2013). Change in Self-Reported Health Status among Immigrants in the United States: Associations with Measures of Acculturation. PLOS ONE, 8, e76494.

Li, J., \& Hummer, R. (2015). The Relationship Between Duration of U.S. Residence, Educational Attainment, and Adult Health Among Asian Immigrants. Population Research and Policy Review, 34, 49-76.

Link, B.G., \& Phelan, J. (1995). Social Conditions As Fundamental Causes of Disease. Journal of Health and Social Behavior, 35, 80-94.

McLaren, L. (2007). Socioeconomic Status and Obesity. Epidemiologic Reviews, 29, 29-48.

Oakkar, E.E., Stevens, J., Bradshaw, P.T., Cai, J.W., Perreira, K.M., Popkin, B.M., et al. (2015). Longitudinal study of acculturation and BMI change among Asian American men. Preventive Medicine, 73, 1521.

Okosun, I.S., Choi, S., Matamoros, T., \& Dever, G.E.A. (2001). Obesity Is Associated with Reduced SelfRated General Health Status: Evidence from a Representative Sample of White, Black, and Hispanic Americans. Preventive Medicine, 32, 429-436.

Oza-Frank, R., \& Narayan, K.M.V. (2010). Overweight and Diabetes Prevalence Among US Immigrants. American Journal of Public Health, 100, 661-668.

Pahl, K., \& Way, N. (2006). Longitudinal trajectories of ethnic identity among urban Black and Latino adolescents. Child Development, 77, 1403-1415.

Pearlin, L.I., \& Bierman, A. (2013). Current Issues and Future Directions in Research into the Stress Process. In C. Aneshensel, J. Phelan, \& A. Bierman (Eds.), Handbook of the Sociology of Mental Health pp. 325-340). Netherlands: Springer.

Pearlin, L.I., Menaghan, E.G., Morton, A.L., \& Mullan, J.T. (1981). The Stress Process. Journal of Health and Social Behavior, 22.

Pérez-Escamilla, R. (2011). Acculturation, nutrition, and health disparities in Latinos. The American Journal of Clinical Nutrition, 93, 1163S-1167S.

Perez, G., \& Cruess, D. (2014). The impact of familism on physical and mental health among Hispanics in the United States. Health Psychology Review, 8, 2014.

Phinney, J.S., \& Ong, A.D. (2007). Conceptualization and measurement of ethnic identity: Current status and future directions. Journal of Counseling Psychology, 54, 271-281.

Portes, A., \& Rumbaut, R.G. (2006). Immigrant America: A Portrait. Berkeley, CA: University of California Press.

Portes, A., \& Zhou, M. (1993). The New Second Generation: Segmented Assimilation and Its Variants. Annals of the American Academy of Political and Social Science, 530, 74-96. 
Preacher, K., \& Hayes, A. (2008). Asymptotic and resampling strategies for assessing and comparing indirect effects in multiple mediator models. Behavior Research Methods, 40, 879-891.

Ramakrishnan, K., \& Ahmad, F. (2014). State of Asian Americans and Pacific Islanders: Immigration. Washington, DC: Center for American Progress.

Redfield, R., Linton, R., \& Herskovits, M. (1936). Memorandum for the study of acculturation. American Anthropologist, 38.

Rivera, F.I., Guarnaccia, P.J., Mulvaney-Day, N., Lin, J.Y., Torres, M., \& Alegria, M. (2008). Family Cohesion and Its Relationship to Psychological Distress Among Latino Groups. Hispanic Journal of Behavioral Sciences, 30, 357-378.

Ro, A. (2014). The Longer You Stay, the Worse Your Health? A Critical Review of the Negative Acculturation Theory among Asian Immigrants. International Journal of Environmental Research and Public Health, 11, 8038-8057.

Ro, A., \& Gee, G.C. (2012). Disability status differentials among Asian immigrants in the United States: The added dimensions of duration and age. Race and Social Problems, 4, 83-92.

Robles, T.F., Glaser, R., \& Kiecolt-Glaser, J.K. (2005). Out of Balance. Current Directions in Psychological Science, 14, 111-115.

Rogler, L.H., Cortes, D.E., \& Malgady, R.G. (1991). Acculturation and mental health status among Hispanics: Convergence and new directions for research. American Psychologist, 46, 585-597.

Rosas, L., Sanchez-Vaznaugh, E., \& Sánchez, B. (2014). Nativity, US Length of Residence, and BMI Among Diverse Asian American Ethnic Groups. Journal of Immigrant and Minority Health, 1-8.

Rosmond, R., Lapidus, L., Mårin, P., \& Björntorp, P. (1996). Mental Distress, Obesity and Body Fat Distribution in Middle-Aged Men. Obesity Research, 4, 245-252.

Sabogal, F., Marin, G., Otero-Sabogal, R., Marin, B.V., \& Perez-Stable, E.J. (1987). Hispanic Familism and Acculturation: What Changes and What Doesn't? Hispanic Journal of Behavioral Sciences, 9, 397412.

Salant, T., \& Lauderdale, D.S. (2003). Measuring culture: a critical review of acculturation and health in Asian immigrant populations. Social Science and Medicine, 57, 71-90.

Sánchez-Vaznaugh, E.V., Kawachi, I., Subramanian, S.V., Sánchez, B.N., \& Acevedo-Garcia, D. (2009). Do Socioeconomic Gradients in Body Mass Index Vary by Race/Ethnicity, Gender, and Birthplace? American Journal of Epidemiology, 169, 1102-1112.

Schwartz, S., Unger, J., Zamboanga, B., \& Szapocznik, J. (2010). Rethinking the Concept of Acculturation: Implications for Theory and Research. The American Psychologist, 65, 237-251.

Tabachnick, B., \& Fidell, L. (2007). Using multivariate statistics. Boston, MA: Pearson/Allyn and Bacon.

Torres, J.M., \& Wallace, S.P. (2013). Migration Circumstances, Psychological Distress, and Self-Rated Physical Health for Latino Immigrants in the United States. American Journal of Public Health, 103, 1619-1627.

Uppaluri, C., Schumm, L., \& Lauderdale, D. (2001). Self-Reports of Stress in Asian Immigrants: Effects of Ethnicity and Acculturation. Ethnicity \& Disease, 11, 107.

Viruell-Fuentes, E.A., Miranda, P.Y., \& Abdulrahim, S. (2012). More than culture: Structural racism, intersectionality theory, and immigrant health. Social Science and Medicine, 75, 2099-2106.

Waters, M. (1990). Ethnic Identities: Choosing identities in America. London, England: University of California Press.

Wheaton, B., Young, M., Montazer, S., \& Stuart-Lahman, K. (2013). Social Stress in the Twenty-First Century. Handbook of the Sociology of Mental Health. New York, NY: Springer.

Williams, D.R., Mohammed, S.A., Leavell, J., \& Collins, C. (2010). Race, socioeconomic status, and health: Complexities, ongoing challenges, and research opportunities. Annals of the New York Academy of Sciences, 1186, 69-101. 
Williams, D.R., Yan Yu, Jackson, J.S., \& Anderson, N.B. (1997). Racial Differences in Physical and Mental Health: Socio-economic Status, Stress and Discrimination. Journal of Health Psychology, 2, 335351.

Yee, B.W.K., Su, J., Kim, S.Y., \& Yancura, L. (2009). Asian American and Pacific Islander Families. In N. Tewari, \& A.A. Alvarez (Eds.), Asian American Psychology: Current Perspectives.

Ying, Y.W., Lee, P.A., \& Tsai, J.L. (2007). Attachment, sense of coherence, and mental health among Chinese American college students: Variation by migration status. International Journal of Intercultural Relations, 31, 531-544.

Zhang, W., Hong, S., Takeuchi, D.T., \& Mossakowski, K.N. (2012). Limited English proficiency and psychological distress among Latinos and Asian Americans. Social Science and Medicine. 75, 1006-1014. 
Research Highlights

- We examine six mediators between duration of U.S. stay and BMI among immigrants.

- There is no association between duration and BMI among Latino or Asian men.

- For Latinas, household income and acculturative stressors are significant pathways.

- For Asian women, English proficiency and discrimination are significant pathways.

- Aspects of acculturation are not associated with BMI in expected directions. 